\title{
The first year of operation of CologneAMS; performance and developments
}

\author{
A. Dewald ${ }^{1, a}$, S. Heinze ${ }^{1, b}$, C. Feuerstein ${ }^{1, c}$, C. Müller-Gatermann ${ }^{1}$, A. Stolz ${ }^{1}$, M. Schiffer ${ }^{1}$, G. Zitzer ${ }^{1}$, T. Dunai ${ }^{2}$, J. \\ Rethemeyer $^{2}$, M. Melles ${ }^{2}, \mathrm{H}$. Wiesel ${ }^{2}$, and F. von Blanckenburg ${ }^{3}$ \\ ${ }^{1}$ CologneAMS/Institute of Nuclear Physics, University of Cologne, Germany \\ ${ }^{2}$ Institute of Geology and Mineralogy, University of Cologne, Germany \\ ${ }^{3}$ German Research Centre for Geosciences, Potsdam
}

\begin{abstract}
In this contribution we report on the measurements performed so far at CologneAMS and on the quality which has been obtained for the isotopes ${ }^{10} \mathrm{Be},{ }^{14} \mathrm{C}$ and ${ }^{26} \mathrm{Al}$. We also describe the procedure developed to measure plutonium-isotopes at CologneAMS and first results for ${ }^{239,240,242} \mathrm{Pu}$ are presented. In addition we report on modifications made on our new TOF device with beam profile capabilities.
\end{abstract}

\section{Introduction}

CologneAMS is a new centre for Accelerator Mass Spectrometry (AMS) at the University of Cologne. The device was built by High Voltage Engineering Europe (HVEE) and has been installed in the existing accelerator area of the Institute of Nuclear Physics. The layout of the facility is shown in Fig.1. A detailed description can be found in (ref.[1],[2]). Sample preparation laboratories were set up at the Institute of Geology and Mineralogy of the University of Cologne and started operation in 2011. It is expected that they will reach their full capacity by 2015. Most of the samples which have been measured at CologneAMS since the acceptance test in 2011 were prepared in the local sample preparation laboratories.

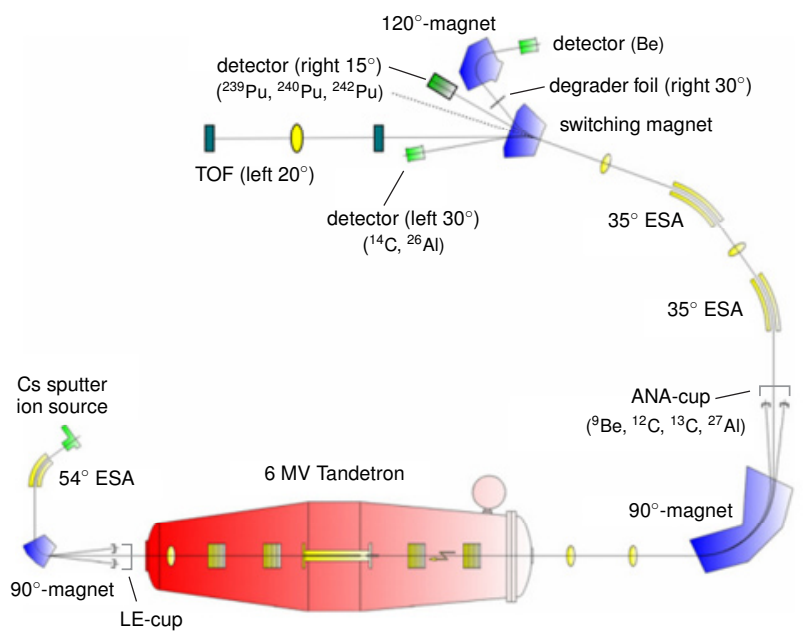

Figure 1. Layout of the AMS-facility

\footnotetext{
a e-mail: dewald@ikp.uni-koeln.de

be-mail: heinze@ikp.uni-koeln.de

ce-mail: feuerstein@ikp.uni-koeln.de
}

\section{Ion optics calculations}

Fig.2 shows ion optics calculations for the high energy mass spectrometer of CologneAMS from the first slits downstream of the accelerator till the entrance window of the detector positioned at the port left $30^{\circ}$ of the switching magnet. Different ion tracks were chosen to represent a phase space of $8 \cdot \operatorname{mm} \operatorname{mrad} \sqrt{\mathrm{MeV}}$. Two beams are shown which differ in mass by $3 \%$. The complete high energy mass spectrometer was found to be almost achromatic with an energy dispersion of $2.1 \mathrm{~mm} / \%$ and a mass dispersion of $24.1 \mathrm{~mm} / \%$ at the detector position. The calculations were performed with the matrix code developed in Cologne LIMIOPTIC II. This code allows to modify input parameters via slide bars. The results of the input variations are displayed simultaneously which simplifies very much the investigation of specific ion optical features of a complex system. We developed for the complete CologneAMS system also the transformations needed to deduce relevant input parameters for LIMIOPTIC II from the real settings of voltages and currents applied to the lenses and magnets and vice versa. The results obtained in this way were surprisingly good and are suited to find optimal settings for the beam tunings.

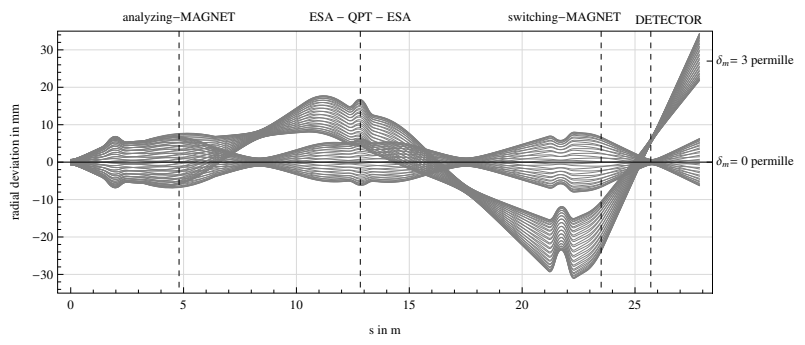

Figure 2. Ion optics calculation for the high energy mass spectrometer. Shown are ion tracks which represent beams which differ in mass by $\delta \mathrm{m}=3 \%$ 


\section{The first routine measurements at CologneAMS}

After successful acceptance tests for the radionuclides ${ }^{10} \mathrm{Be},{ }^{14} \mathrm{C},{ }^{26} \mathrm{Al},{ }^{36} \mathrm{Cl}$ and ${ }^{129} \mathrm{I}$ ([2]) the routine operation started in 2011. Details of these routine measurements are summarized in table 1 . So far about $1400{ }^{14} \mathrm{C}$ samples were measured including standard and blank samples. The typical measuring time is about 1 hour/sample. The precision reached for samples with an isotopic ratio $\geq 5 \cdot 10^{-13}$ is $0.4 \%$. The blank values given in table 1 refer to chemically treated sample material. The pure machine blank is estimated to be lower by at least one order of magnitude. In some cases minor components of ${ }^{7} \mathrm{Li}$ ions are detected in the ionization detector but these events can be very well separated from the ${ }^{14} \mathrm{C}$ events. The detector used for ${ }^{14} \mathrm{C}$ measurements is mounted at the port left $30^{\circ}$ of the switching magnet (see also Fig.1). The reproducibility of the measured NIST oxalic acid (OX-II) standards was determined to $0.4 \%$. In Fig. 3 the measured values of 56 OX-II standards are in chronological order. The variance determined from these values corresponds nicely to the experimental errors of the individual measured isotopic ratios. Therefore it can be deduced that no significant systematic error is present.

For ${ }^{10} \mathrm{Be}$ about 380 samples were measured so far. Like in the cases of ${ }^{14} \mathrm{C}$ also for ${ }^{10} \mathrm{Be}$ the typical measuring time was 1 hour/sample. The ${ }^{10} \mathrm{Be}$ ions are detected with an ionization detector mounted downstream of the $120^{\circ}$ magnet which is positioned downstream of the switching magnet (see also Fig. 1). At this position the degrader foil technique can be used which employs a $1 \mu \mathrm{m}$ thick $\mathrm{Si}_{3} \mathrm{~N}_{4}$ foil located between the switching magnet and the entrance of the $120^{\circ}$ magnet. After the degrader foil the ${ }^{10} \mathrm{Be}$ ions in the $4^{+}$charge state are sent to the ionization detector. By using this degrader technique in combination with the double focusing magnet a very efficient suppression of the isobar ${ }^{10} \mathrm{~B}$ is achieved. The price for the good isobar suppression is a reduced ${ }^{10} \mathrm{Be}$ intensity arriving at the detector which results in an overall correction factor of 2.0 which has to be applied to get the nominal ${ }^{10} \mathrm{Be} /{ }^{9} \mathrm{Be}$ ratios of the standard samples. In some cases very small components of ${ }^{25} \mathrm{Mg}$ are registered in the detector but there is no interfering component close to the ${ }^{10} \mathrm{Be}$ detection region. For unknown samples with isotopic ratios $\geq 10^{-12}$ a precision of $3 \%$ is reached. The reproducibility of the isotope ratios $\geq 5 \cdot 10^{-12}$ is $1 \%$, see Fig.4. The third radionuclide measured routinely is ${ }^{26} \mathrm{Al}$. So far $120 \mathrm{Al}$ samples have been measured. Also for this radionuclide a measuring time of 1 hour/sample is used. The precision reached for samples with isotopic ratios $\geq 10^{-12}$ is $3 \%$. A correction factor of 1.1 has to be used to reproduce the nominal isotopic ratios of the standard samples for which a reproducibility of $1 \%$ is obtained (for isotopic ratios $\geq 5 \cdot 10^{-12}$ ). The ${ }^{26} \mathrm{Al}$ measurements were performed by extracting atomic negative $\mathrm{Al}$ ions out of the sputter source. The typical beam currents which can be obtained in this way are rather low, typically about 100nA. We measure very clean spectra in the ionization detector at port left $30^{\circ}$ of the switching magnet with no indication of any interfering component. As standard material we used three different standards prepared by $\mathrm{K}$. Nishiizumi with the nominal isotopic ratios of $1.065 \cdot 10^{-11}, 1.818 \cdot 10^{-12}$ and $4.990 \cdot 10^{-13}$. The measured values were found to be $1.061(5) \cdot 10^{-11}, 1.845(25) \cdot 10^{-12}$ and $4.90(13) \cdot 10^{-13}$, respectively. The same correction factor of 1.1 was applied for all standards.

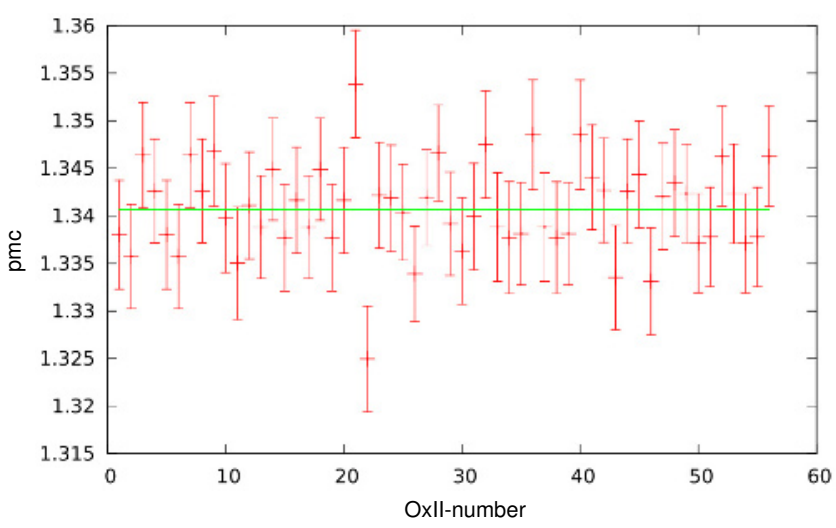

Figure 3. Measured pmc-values of our first 56 OX-II-samples, ordered chronologically

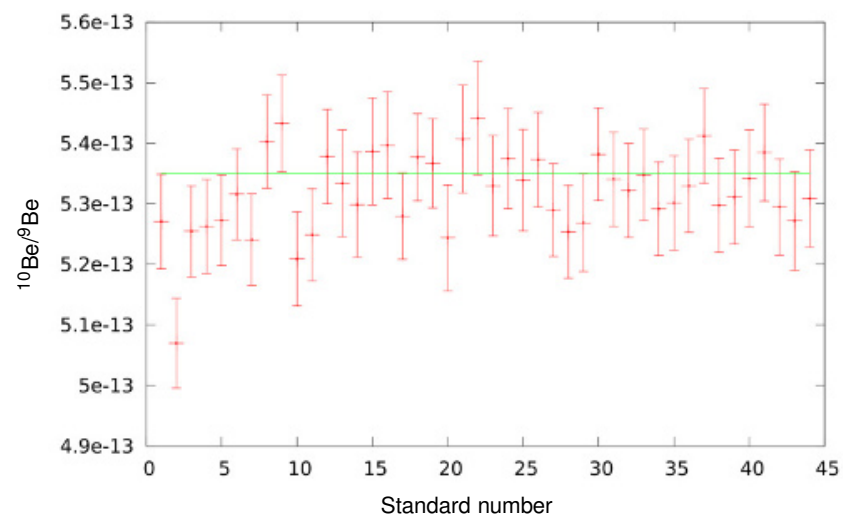

Figure 4. ${ }^{10} \mathrm{Be} /{ }^{9} \mathrm{Be}$ isotope ratios of our first 44 berylliumstandard-samples, ordered chronologically

\section{Development of AMS plutonium measurements}

For Plutonium it is not possible to use the same method that is used for standard AMS measurements because no stable isotope exists for which the current could be measured with a Faraday cup as a reference for the corresponding radionuclide intensity. In order to measure the isotopic ratios of plutonium isotopes it is required to change the machine tuning sequentially for every isotope so that they can reach the gas ionization detector. For a fast and reliable change of the settings it is ideal when only electrostatic elements have to be modified. This is possible when the momentum over charge ratio is identical for all isotopes of interest at the high-energy side. By changing the terminal voltage accordingly this can be achieved. Hence only the bouncer voltage at the injector magnet, the terminal voltage and the voltage of the high-energy electrostatic analysers need to be changed. 
Table 1. Details of the routine measurements for the radionuclides ${ }^{10} \mathrm{Be},{ }^{14} \mathrm{C}$ and ${ }^{26} \mathrm{Al}$,

\begin{tabular}{lcccccc}
\hline $\begin{array}{l}\text { Radio- } \\
\text { nuclide }\end{array}$ & $\begin{array}{c}\text { Terminal voltage } \\
\text { /charge state }\end{array}$ & $\begin{array}{c}\text { Current at LE-cup } \\
\text { /transmission LE- to ANA-cup }\end{array}$ & $\begin{array}{c}\text { Reproducibility } \\
\text { of standards }\end{array}$ & Blank values & $\begin{array}{c}\text { Correction } \\
\text { factor }\end{array}$ & $\begin{array}{c}\text { Precision of } \\
\text { isotope ratio } R\end{array}$ \\
\hline${ }^{14} \mathrm{C}$ & $5.5 \mathrm{MV} / 4^{+}$ & $40-50 \mu \mathrm{A}$ (elect.) $/ 50 \%$ & $0.4 \%$ & $\begin{array}{c}1-2 \cdot 10^{-15} \text { (organic) } \\
<1 \cdot 10^{-15} \text { (carbonate) }\end{array}$ & 1.20 & $0.4 \%$ for $R \geq 5 \cdot 10^{-13}$ \\
& & $1.5 \mu \mathrm{A}$ (elect.) $/ 50 \%$ & $1 \%$ & $1.5 \cdot 10^{-15}$ & 2.0 & $3 \%$ for $R \geq 5 \cdot 10^{-12}$ \\
${ }^{10} \mathrm{Be}^{1)}$ & $4.5 \mathrm{MV} / 2^{+}$ & $100 \mathrm{nA}$ (elect.) $/ 36 \%$ & $1 \%$ & $5 \cdot 10^{-16}$ & 1.1 & $3 \%$ for $R \geq 5 \cdot 10^{-12}$ \\
\hline
\end{tabular}

1) Degrader foil technique with $120^{\circ}$-magnet (for $4^{+}$charge state); ion extracted from source: $\mathrm{BeO}^{-}$2) No interferences

As a pilot beam ${ }^{238} \mathrm{U}$ was selected because of its pronounced similarity to plutonium and it is possible to prepare samples with sufficient concentration so that its intensity can be measured easily in a Faraday cup. From the ion source the molecules $\mathrm{PuO}^{-}$and $\mathrm{UO}^{-}$are selected and injected into the accelerator. The technique that was used for sample preparation is based on the method described in ref.[3]. For us it turned out that best results were obtained by mixing the plutonium (precipitated in an iron oxide matrix) with niobium at a mass ratio of 1:4.

Different machine settings were tested to find the optimum charge state for our device. Finally the $3^{+}$charge state was selected because of low interferences observed in the detector and because of a rather high transmission. The transmission from the low energy cup, upstream of the accelerator, to the analyzer cup downstream of the analyzer magnet was determined with the pilot beam and was found to be $14.6 \%$. The analyzer magnet limits the terminal voltage to about $3 \mathrm{MV}$ which is close to the ideal value for the $3^{+}$charge state.

Uranium and plutonium ions were registered in a gas ionization detector originating from an AMS setup at the University of Utrecht. The detector was slightly modified for our purposes. The entrance window was put on negative potential with respect to the Frisch grid in order to improve the collection of electrons which are generated close to the entrance window. The detector has then been mounted at the port right $15^{\circ}$ of the switching magnet. (Fig.1) The best resolution (6.3\%) was achieved using a gas pressure of 23 mbar isobutane and voltages of +300 $\mathrm{V},+100 \mathrm{~V}$ and $-100 \mathrm{~V}$ for anode, grid and cathode respectively. The obtained resolution is sufficient to clearly separate the plutonium peak from the lower energy peaks which were also observed. These $\mathrm{m} / \mathrm{q}$ interferences probably belong to ${ }^{160} \mathrm{Dy}^{2+},{ }^{160} \mathrm{Gd}^{2+},{ }^{80} \mathrm{Se}^{1+}$ and molecular ions of the same mass and charge state.

The samples of the first plutonium measurement were spiked with ${ }^{242} \mathrm{Pu}$ to determine the absolute concentrations of ${ }^{239} \mathrm{Pu}$ and ${ }^{240} \mathrm{Pu}$. A measuring sequence consisted of measuring the spike isotope for seven seconds and the other isotopes for twenty seconds each separated by a switching time of five seconds. The switching time can be reduced to two or three seconds. Six runs consisting of fifteen sequences were performed for every sample resulting in an effective measuring time of 70 minutes for every sample.

As standard material we used the Centro Nacional de Aceleradores (CNA) standard which was originally manu-

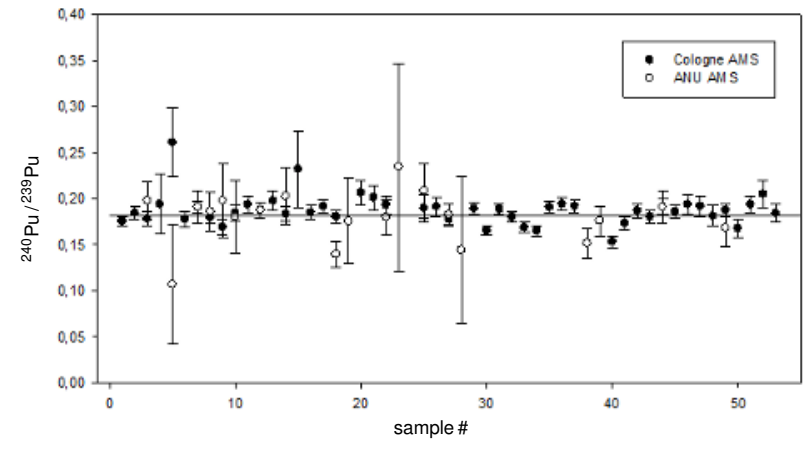

Figure 5. Comparison of $\mathrm{Pu}$ isotope-ratios ${ }^{240} \mathrm{Pu} /{ }^{239} \mathrm{Pu}$ measured at CologneAMS (closed circles) and ANU (open circles). Identical sample material was used at both laboratories, sample preparation was done individually but follows the same procedure

factored by E. Chamizo. It was provided by ETH Zürich, see ref.[4] for the corresponding ratios and further information. The isotopic ratios of standards were measured with a reproducibility of $2.3 \%$. To obtain the nominal isotope ratios correction factors had to be used which varied in the $5 \%$ range.

Figure 5 shows the ${ }^{240} \mathrm{Pu} /{ }^{239} \mathrm{Pu}$-ratios measured for 54 $\mathrm{Pu}$ samples. These results are compared to measurements performed at ANU Canberra (20 samples) using the same sample material, soil from farmland of South Africa. The acquired ${ }^{240} \mathrm{Pu} /{ }^{239} \mathrm{Pu}$-ratios of these samples (Fig. 5) result in a mean of $0.181 \pm 0.001$ for CologneAMS and $0.176 \pm$ 0.005 for ANU Canberra. These values are very close to the value of 0.180 known for the global plutonium fallout. The blank samples contained in the batch also produced a count rate of 1 count per minute ${ }^{239} \mathrm{Pu}$ and 1.5 counts per minute ${ }^{240} \mathrm{Pu}$. This is comparable to what has been measured at ANU.

The application of our first measurement is presented in Fig. 6 and shows the plutonium activity of the examined farmland, calculated from the sum of the absolute concentrations of ${ }^{240} \mathrm{Pu}$ and ${ }^{239} \mathrm{Pu}$ content, as a function of the years of cultivation. The results of CologneAMS and ANU Canberra are again in excellent agreement within experimental errors. The graph shows the expected behavior caused by soil erosion that was found with the tracer nuclide ${ }^{137}$ Cesium as well (ref. [5]).

In future we will work on the suppression of crosstalk between ${ }^{238} \mathrm{U}$ and ${ }^{239} \mathrm{Pu}$. This would allow for a better background correction and therefore higher accuracy especially of low activity samples. Our new time of flight system might be used for that purpose. 


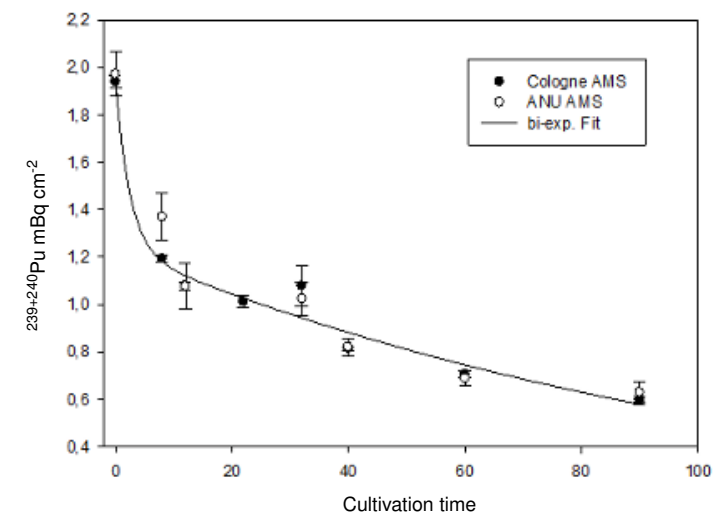

Figure 6. ${ }^{239+240} \mathrm{Pu}$ activity determined from the absolute concentration of the measured ${ }^{239} \mathrm{Pu}$ and ${ }^{240} \mathrm{Pu}$ concentrations in soil samples of farmland in Tweespruit (South Africa) as a function of cultivation time. Shown are the experimental values measured independently at CologneAMS and ANU as well as a line to guide the eye

\section{Time-of-flight system with beam profile capabilities}

We developed further our TOF-system which is described in its first variant in ref. [6] and consists of two identical beam profile monitors based on microchannel plates. In order to allow for larger flight distances between the start and stop detector we introduced a magnetic quadrupole lens with an inner pole diameter of $8 \mathrm{~cm}$. This lens is used to refocus the beam which is scattered by a degrader foil positioned close to the start detector. The refocusing is illustrated in fig. 7 where the beam profile of a ${ }^{14} \mathrm{C}$ beam at $27.5 \mathrm{MeV}$ degraded by a $1 \mu \mathrm{m}$ thick $\mathrm{Si}_{3} \mathrm{~N}_{4}$ foil is shown with lens on and off, measured with detector 2 .

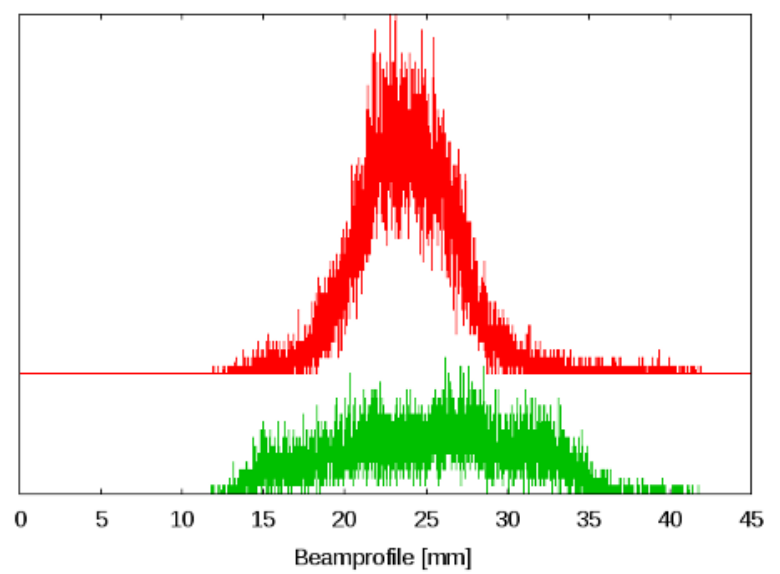

Figure 7. Beamprofiles of ${ }^{14} \mathrm{C}$ ions measured with the second detector of the TOF system with (upper) and without (lower) use of the quadrupole lens in the middle of the flight path

In a first test setup, shown in fig. 8 the separation of the detectors is $2.4 \mathrm{~m}$. It is planned to use later larger flight distances (up to $4 \mathrm{~m}$ ) for a better mass separation. With the actual setup a factor of 2 in detection efficiency was observed by using the quadrupole lens. The total time resolution depends strongly on the thresholds of the constant fraction discriminators, with a reasonable detection efficiency the experimental time resolution is about $600 \mathrm{ps}$.

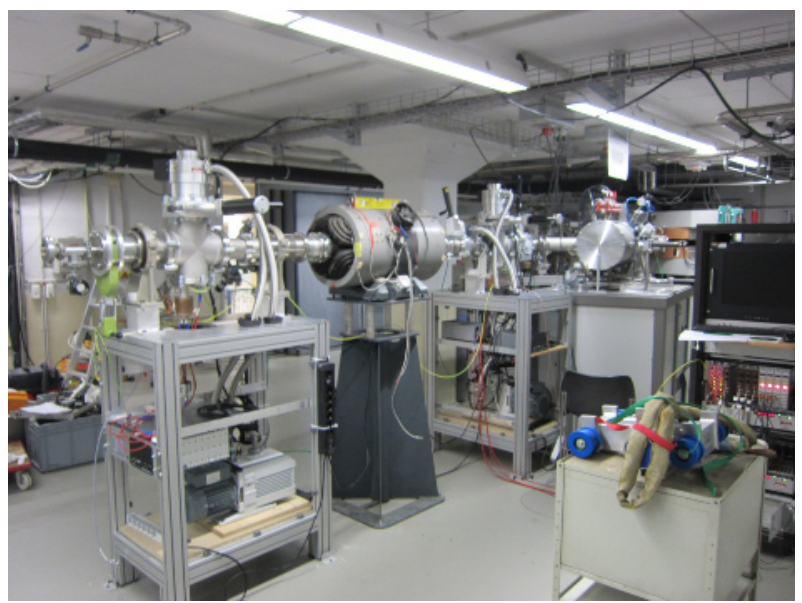

Figure 8. Time of flight beamline at port left $20^{\circ}$ of the switching magnet. Shown are the two beam profile monitors in the crosspieces separated by a distance of $2.4 \mathrm{~m}$ and the quadrupoledoublet in between

\section{Acknowledgements}

We would like to thank Keith Fifield for his help during the first Pu measurements and W. Kreuzer for technical support with the manuscript as well as Ch. Fransen and K.O. Zell for reading the manuscript. This work was supported by the DFG (Germany) under the Contract No.: ME 1169/19-1.

\section{References}

[1] M.G. Klein, A. Dewald, A. Gottdang, S. Heinze, D. J. W. Mous, proceedings of the conference: ECAART-10, Athens, (2010)

[2] A. Dewald, S. Heinze, J. Jolie, A. Zilges, T. Dunai, J. Rethemeyer, M. Melles, M. Staubwasser, B. Kuczewski, J. Richter, U. Radtke, F. von Blanckenburg, M. Klein, Nucl. Instr. and Meth.B 294, 18 (2013)

[3] S.E. Everett, S.G. Tims, G.J. Hancock, R. Bartley, L.K. Fifield, Jour. of Env. Radioact. 99, 383 (2008)

[4] M. Christl, C. Vockenhuber, P.W. Kubik, L. Wacker, J. Lachner, V. Alfimov, H.-A. Synal, Nucl. Instr. and Meth.B 294, 29 (2013)

[5] Dr. Hendrik Wiesel, Bestimmung langlebiger kosmogener $\left({ }^{10} \mathrm{Be},{ }^{26} \mathrm{Al}\right)$ und anthropogener $\left({ }^{137} \mathrm{Cs}\right.$, 238,239,240 Pu) Radionuklide in Umweltproben mittels $\alpha$ , $\gamma$ - und Beschleuniger-Massen-Spektrometrie zur Untersuchung geologischer Vorgänge (PhD Thesis, University of Cologne, 2013) 44

[6] G. Pascovici, A. Dewald, S. Heinze, L. Fink, C. Müller-Gatermann, M. Schiffer, C. Feuerstein, M. Pfeiffer, J. Jolie, S. Thiel, K.O. Zell, O. Arnopolina, F. von Blanckenburg, Nucl. Instr. and Meth.B 294, 410 (2013) 